\title{
PVSyst ile Konya İlinde Sabit ve Çift Eksenli Güneş Takip Sisteminin Modellenmesi
}

\author{
Ayşegül Etci ${ }^{1}$, Ayşe Kocalmış Bilhan ${ }^{2}$ \\ 1 Tedaş Genel Müdürlüğü, Ankara, Türkiye (ORCID: 0000-0002-5641-5518), aysegul.etci@tedas.gov.tr \\ ${ }^{2 *}$ Nevşehir H.B.V. Üniversitesi, Mühendislik Mimarlık Fakültesi, Elektrik Elektronik Mühendisliği Bölümü, Nevşehir, Türkiye \\ (ORCID: 0000-0002-5008-6784), akbilhan@nevsehir.edu.tr
}

(International Conference on Design, Research and Development (RDCONF) 2021 - 15-18 December 2021)

(DOI: 10.31590/ejosat.1039800)

ATIF/REFERENCE: Etci A., Bilhan A. K., (2021), PVSyst ile Konya İlinde Sabit ve Çift Eksenli Güneş Takip Sisteminin Modellenmesi, Avrupa Bilim ve Teknoloji Dergisi, (32), 142-147.

$\ddot{O} \mathbf{z}$

Enerji talebindeki hızlı artış ve fosil yakıt kaynaklarının sınırlılığı güvenilir ve temiz enerji kaynaklarına duyulan ihtiyacı artırmıştır. Alternatif enerji kaynaklarından biri olan güneş ışınımı kullanan fotovoltaik (FV) sistemler ise gelecekteki küresel elektrik üretimini karşılamak için kullanılacak olan ana yöntemlerden biridir. Türkiye coğrafi konumu nedeniyle güneş enerjisinin kullanılması açısından oldukça avantajlıdır. Güneş harita potansiyeli incelendiğinde birçok farklı bölge de güneş enerji santralinin kurulabilmektedir. Bu çalışma güneş enerji potansiyeli yüksek olduğu için Konya ili seçilmiştir. PVSyst yazılım program ile sabit eksenli veya çift eksenli güneş takip sistemi kullanılması durumunda Konya ilindeki güneş enerji potansiyeline ait analiz yapılmıştır. Kullanılan bu program farklı çeşitteki güneş takip sistemlerinin analizi karşılaştıılmıştır. Aynı işlem farklı şehirler için güncel veriler kullanılarak yapılabilir.

\section{Modeling of Fixed and Dual Axis Solar Tracking Systems in Konya by Using Pvsyst}

\begin{abstract}
The rapid increase in energy demand and the limitation of fossil fuel resources have increased the need for reliable and clean energy sources. Photovoltaic (PV) systems using solar radiation, which is one of the alternative energy sources, is one of the main methods to be used to meet the future global electricity production. Turkey is very advantageous in terms of using solar energy due to its geographical location. When the solar map potential is examined, solar power plants can be established in many different regions. Konya was chosen as the city of this study because of its high solar energy potential. In the case of using a fixed-axis or dual-axis solar tracking system with the PVSyst software program, an analysis of the solar energy potential in Konya was made.This program was used to compare the analysis of different types of solar tracking systems. The same analysis can be done for different cities by using the updated information.
\end{abstract}

Keywords: Solar energy, Solar tracking system, PVSyst.

\footnotetext{
*Sorumlu Yazar: akbilhan@nevsehir.edu.tr
} 


\section{Giriş}

Günden güne daha belirgin hale gelen enerji ihtiyacı ve çevre kirliliği, yenilenebilir enerji kaynaklarının karbon kaynaklı enerji kaynaklarının yerini alma sürecini hızlandırmıştır (Nunes, Silva, Pombo, Mariano \& Calado, 2020 ). Küresel ısınma, artan enerji talebi, çevre kirliliğinin önüne geçilmek istenmesi gibi faktörler ülkeleri yeni ve temiz enerji kaynakları arayışına sürüklemiştir. Bu nedenle dünya genelinde hem alternatif enerji kaynaklarının kullanılması hem de geliştirilmesi teşvik edilmektedir. Son yıllarda güneş ışınları kullanılarak elde edilen elektrik enerji hızlı bir tırmanışa geçmiştir. Bunun temel sebebi hem temiz bir enerji kaynağı olması hem atık ürün üretmemesi hem de ücretsiz bir enerji kaynağı olmasıdır. Uygun şartların ve donanımın sağlanmasıyla güneşin olduğu her yerde güneş ışınları elektrik enerjisine dönüştürülebilmektedir. $\mathrm{Bu}$ açıdan incelendiğinde ülkemiz coğrafi açıdan oldukça avantajlı bir konuma sahiptir. Ülkemiz $36^{\circ}$ ile $42^{\circ}$ kuzey enlemleri ve $26^{\circ}$ ile $45^{\circ}$ doğu boylamları coğrafi konumu ile güneş kuşağı içerisinde yer alır. Bu durum Şekil 1 ile gösterilmektedir (MGM, 2021).

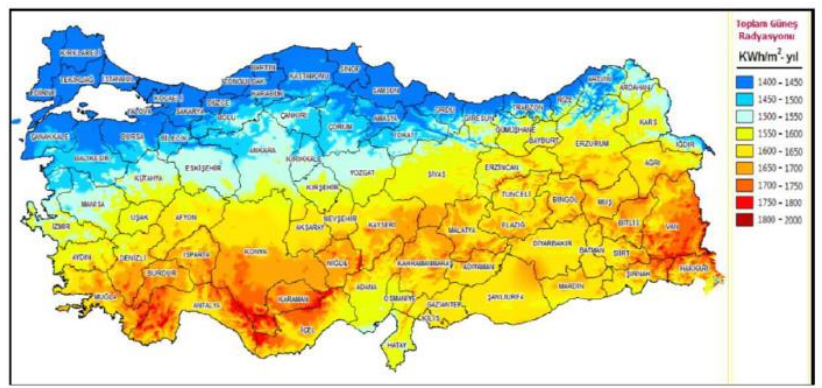

Şekil 1. Türkiye güneş enerjisi potansiyel atlası

Şekil 1 ile verilen ülkemize ait güneşlenme potansiyeli incelendiğinde Türkiye'nin büyük bir kısmında güneş enerjisi üretilmesi konusunda avantajlı olduğu söylenebilir. Yıllık güneşlenme oranları incelendiğinde, yıl içerisinde yaklaşık 110 gün gibi yüksek bir güneş enerjisi potansiyeline sahiptir. Yapılan çalışmalarda yıllık toplam ortalama güneşlenme süresinin 2640 saat (günlük toplam 7,2 saat) olduğu tespit edilmiştir. Bunun yanı sıra, yıllık ortalama ışınım şiddetinin $1.311 \mathrm{kWh} / \mathrm{m}^{2}$, günlük 1şınım şiddetinin ise toplam $3,6 \mathrm{kWh} / \mathrm{m}^{2}$ olduğu tespit edilmiştir. Şekil 2 ile Türkiye genelinde aylık güneşlenme ve radyasyon değerleri sırasıyla (a) ve (b) ile gösterilmektedir (MGM, 2021).

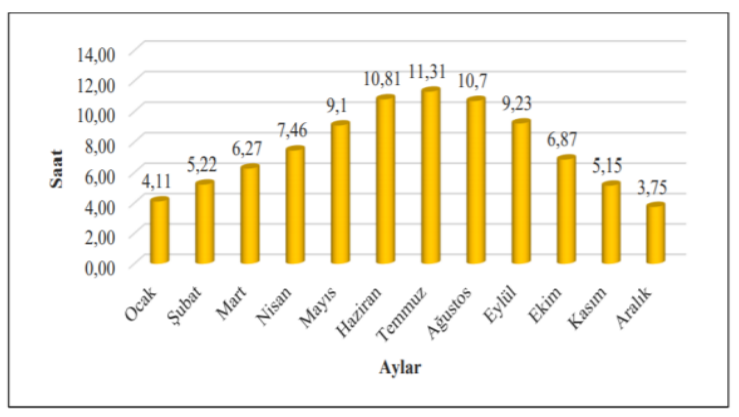

(a)

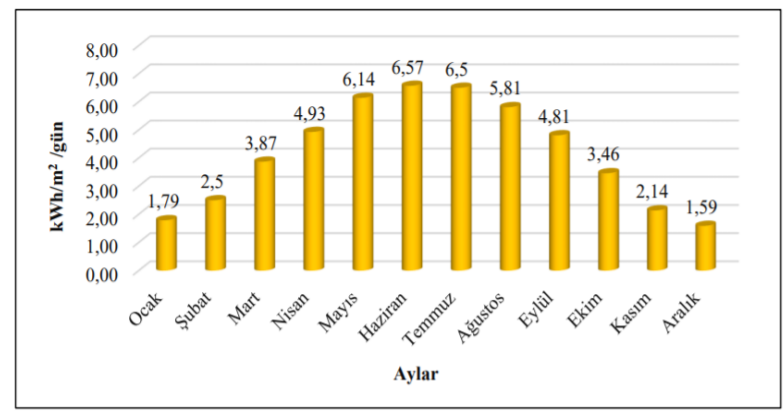

(b)

Şekil 2. (a) Türkiye'nin Aylık Güneşlenme Süresi, (b) Türkiye'nin Aylık Radyasyon Değeri

TEİAŞ'ın 2021 yılı Mart ayı verilerine göre, Türkiye'de üretilen enerjiye ait kurulu güç 9.7069,7 MW olarak ölçülmüştür bu durum Grafik 1 ile gösterilmektedir.. Bunun yanı sıra üretilen bu enerjinin 6.964 MW'1 7779 güneş enerji santrali kullanılarak elde edilmektedir. TEİAŞ'ın aylık olarak hazırladığı raporlar incelendiğinde 2018 yılı sonunda güneş enerjisi kullanılarak elde edilen toplam güç 81,7 MW iken Mart 2021 itibariyle 6.964 MW'a yükselmiş ve her geçen gün yeni kurulan veya devreye alınan güneş enerji santrali (GES) ile güneş enerjisi kullanılarak elde edilen enerji artmaktadır ( TEİAŞ, 2021).

Grafik. 1 Mart 2021 Türkiye'de Kurulu Güç Dağılımı

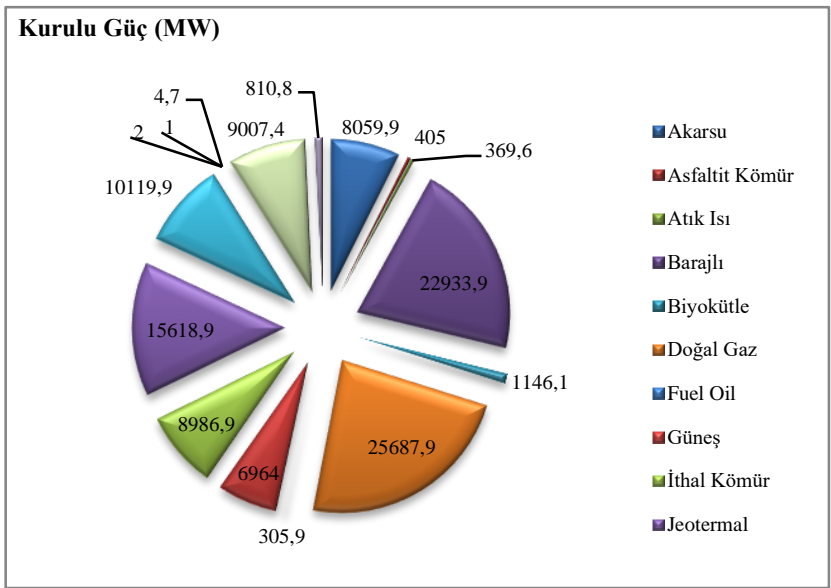

\section{Materyal ve Metot}

\subsection{Fotovoltaik Hücre ve Elektriksel Modeli}

En basit haliyle güneş enerjisi; güneşin çekirdeğindeki helyum gazının hidrojen gazına dönüşmesi sırasında açığa çıkan 1şıma enerjisidir. Güneş enerji şiddeti atmosferimizin dışında, yaklaşı $1370 \mathrm{~W} / \mathrm{m}^{2}$ değerindeyken, yeryüzüne yaklaştıkça bu değer $0-1100 \mathrm{~W} / \mathrm{m}^{2}$ arasında değişim göstermektedir (MGM, 2021). Bu enerjinin dünyaya gelen küçük bir bölümü dahi, insanlığın mevcut enerji tüketiminden kat kat fazladır. Özellikle 1970'lerden sonra yarı iletken teknolojisindeki gelişmeler, malzeme biliminin gelişimi sayesinde güneş enerjisinden yararlanma konusundaki çalışmalar hız kazanmıştır. Bu sayede güneş enerjisi sistemleri günden güne teknolojik olarak ilerlerken, temiz bir enerji kaynağ 1 olarak kendini kabul ettirmişstir (TEİAŞ, 2021; Uzunok, 2007). Şekil 3 ile tek bir fotovoltaik hücreye ait elektriksel devre; bir akım kaynağına ters 
paralel bağlı bir diyot, paralel bağlı direnç (kaçak akım direncini temsil etmekte- $R_{p}$ ) ve seri bağlı bir direnç (hücre iç direnci ve bağlantı dirençlerini temsil etmekte- $\mathrm{R}_{\mathrm{s}}$ ) ile gösterilmektedir (Cuce, Karakaş ve Bali, 2017).

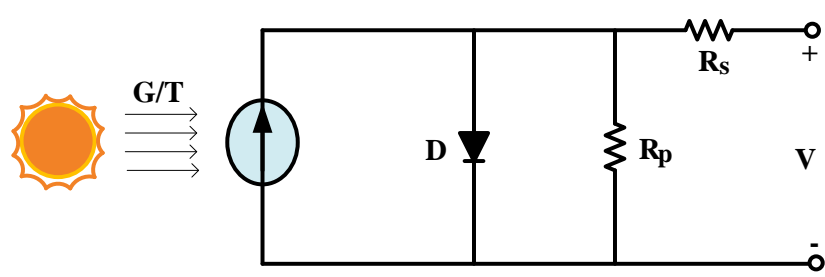

Şekil 3. Tek bir fotovoltaik hücreye ait elektriksel devre șeması

Şekil 3 ile gösterilen devre şemasında Kirchhoff'un akımlar kanunu uygulanır ise fotovoltaik hücreden elde edilecek akım miktarı Denklem 1 ile hesaplanabilir (İşen, 2020; Adak, Cangi ve Yılmaz, 2019; Kırcığlu, Yıldız, 2015).

$$
\mathrm{I}=\mathrm{I}_{\mathrm{ph}}-\mathrm{I}_{\mathrm{d}}-\mathrm{I}_{\mathrm{sh}}
$$

Denklem 1'de I; fotovoltaik hücreye ait akımı, $\mathrm{I}_{\mathrm{ph}}$; hücrenin 1şıtan elektrik üretme kapasitesini, $\mathrm{I}_{\mathrm{d}}$; diyottan geçen akımı ve $\mathrm{I}_{\mathrm{sh}}$; paralel direnç üzerinden geçen kaçak akıyı göstermektedir. Denklem 2, 3 ve 4 ile Iph, $I_{d}$ ve $I_{\text {sh }}$ akımlarının hesaplanmasına ait eşitlikler verilmektedir. $\left(\mathrm{G}_{\mathrm{n}}\right.$ standart test koşullar içinde kabul edilen 1 şınım değeridir ve bu değer $1000 \mathrm{~W} / \mathrm{m}^{2}$ 'dir, G; anlık ışınım değeri, T; Kelvin cinsinden hücre sıcaklık değeri, $\mathrm{I}_{0}$; diyotun sızıntı akım değeridir)

$$
\begin{aligned}
& \mathrm{I}_{\mathrm{ph}}=\frac{\mathrm{G}}{\mathrm{G}_{\mathrm{n}}}\left[\mathrm{I}_{\mathrm{phn}}+\alpha\left(\mathrm{T}-\mathrm{T}_{\mathrm{n}}\right)\right] \\
& \mathrm{I}_{d}=\mathrm{I}_{\mathrm{o}} \cdot\left[\exp \left(\frac{\mathrm{q}\left(\mathrm{V}+\mathrm{IR}_{\mathrm{s}}\right)}{\mathrm{NKT}}\right)\right] \\
& \cdot \mathrm{I}_{s h}=\frac{\mathrm{V}+\mathrm{IR}_{\mathrm{s}}}{\mathrm{R}_{\mathrm{sh}}}
\end{aligned}
$$

Denklem 1'de Denklem 2, 3 ve 4'ün yerleştirilmesiyle de bir fotovoltaik hücreye ait akım gerilim (I-V) ifadesi elde edilebilir. Bu durum Denklem 5 ve 6 ile gösterilmektedir.

$$
\begin{aligned}
& I=I_{p h}-I_{0} \cdot\left[\exp \left(\frac{q\left(V+I R_{s}\right)}{N K T}\right)-1\right]-\frac{V+I R_{s}}{R_{s h}} \\
& V=\frac{N K T}{q}\left[\frac{I_{p h}+I_{d}-I}{I}\right]-R_{s} I
\end{aligned}
$$

$\mathrm{Bu}$ denklemlerde, $\mathrm{q}$; bir elektron yükünü ( $\mathrm{q}=1,6.10-19), \mathrm{N}$; diyot ideallik faktörünü $(\mathrm{N}=1,2), \mathrm{K}$, boltzman sabitini $(\mathrm{K}=1,38.10-23 \mathrm{j} / \mathrm{K})$ ifade etmektedir. Her bir fotovoltaik hücrenin ürettiği gerilim yaklaşık olarak $0,5 \mathrm{~V}$ ile $0,7 \mathrm{~V}$ arasında değişmektedir. $\mathrm{Bu}$ nedenle istenilen gerilim seviyesine ulaşmak için hücrelerin birbirileri ile seri ve paralel bağlanarak fotovoltaik panelleri oluştururlar (Kocalmış Bilhan, Çalışkan ve Ünal, 2016). Bu durum Şekil 4 ile gösterilmektedir.

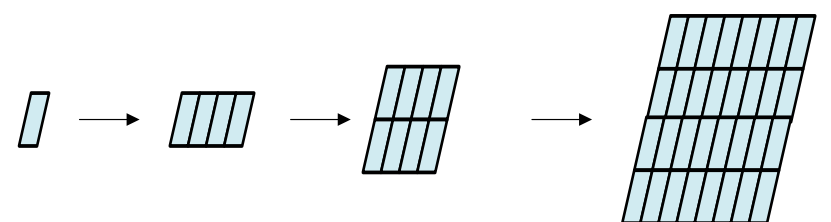

Sekil 4. Tek Bir Fotovoltaik Hücrenin Fotovoltaik Panele Dönüşümü

Bir fotovoltaik (FV) panelden elde edilecek gerilimin miktarı hava koşullarına bağlı olduğu kadar güneşin konumuna da bağlıdır. Yapılan çalışmalarda güneşli ve tam açık havada foton akımının en fazla olduğu fakat bulutlu havalarda güneşten gelen ışımanın az olması durumunda akımın daha düşük olduğu tespit edilmiştir. Bu nedenle sabit (durağan) PV panellerin yerine günümüzde tek eksenli (dikey-yatay) yada iki eksenli (yatay ve düşeyde iki eksenli hareket edebilen) güneşi takip eden yapılar geliştirilmiştir. Her üç yapının kullanım alanına göre farklı avantaj ve dezavantajları bulunmaktadır (Oral, Uçan, 2012; Sarsic1, 2020).

Bu çalışmada; PVSystV 6.43 yazılım programı kullanılarak, Konya İli, Selçuk Üniversitesi kampüsünün enerji ihtiyacının fotovoltaik sistemlerle karşılanması amaçlanmıştır. Sabit eksen ve çift eksen güneş takip sistemi şeklinde tasarlanmış olan sistemlerin üreteceği enerji miktarları ve performansı üzerine değerlendirmeler yapılabilen benzetim yapılması amaçlanmıştır. PVsyst yazılım programında Kampüsün coğrafi konumu belirtilerek program içerisinde yer alan Meteonorm 7.2 veri tabanı ile bölgenin meteoroloji verileri yapay olarak üretilmiştir (Demirtaş, 2006; Aksangör, 2019). İki sistemin yıllık üretim verileri karşılaştırılmıştır.

\subsection{Konya İlindeki Güneş Enerjisi Potansiyeli}

Türkiye'nin İç Anadolu Bölgesinde bulunan Konya ilinde güneşlenme potansiyeli coğrafi özelliklerinden dolayı oldukça yüksektir. Şekil 5 ile Konya iline ait güneş enerjisi potansiyel atlası verilirken Şekil 6'da aylık güneşlenme ve radyasyon değerleri verilmiştir. Konya ilinde karasal iklim hüküm sürmekte olup, yazlar sıcak ve kurak, kışlar soğuk, sert ve yağışlı geçmektedir. Konya ilinin rakımı ise 1170 metredir.

$\mathrm{Bu}$ çalışma da Selçuk Üniversitesi kampüsü için GES üretim santrali modellenmiş ve üretim verileri karşılaştırılmıştır. $\mathrm{Bu}$ santralin coğrafi konumu $38^{\circ}$ kuzey enlemi ve $32.5^{\circ}$ doğu boylamı koordinatında bulunmaktadır (MGM,2021; TEİAŞ, 2021).

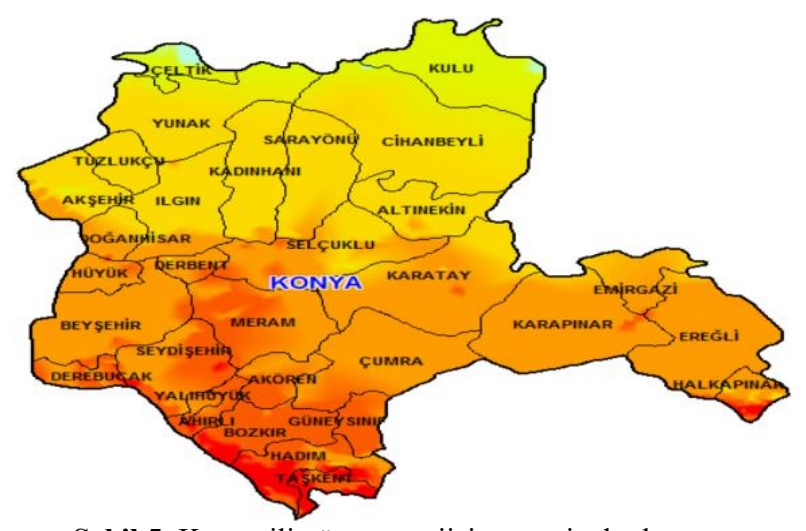

Şekil 5. Konya ili güneş enerjisi potansiyel atlası 


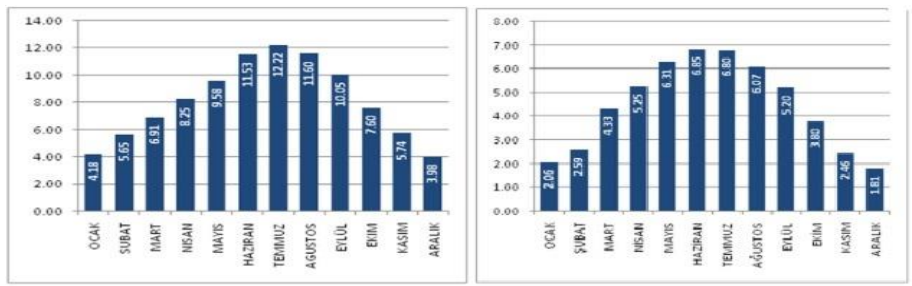

Şekil 6. Konya ili güneşlenme süresi, global radyasyon değeri

\subsection{PVSyst Benzetim Programı}

PVsyst programı, İsviçre Cenevre Üniversitesi tarafindan geliştirilen bir benzetim program türüdür. Bu program sayesinde şebekeye bağlı veya bağımsız PV sistemlerin, PV kullanılan sulama sistemlerinin veya DC şebekeler gibi PV sistem tasarımları yapılarak sonuçları incelenebilmektedir. Bu program diğer programlar ile kıyaslandığında detaylı hesaplamaların yapılmasına ve farklı parametrelerin kullanılmasına olanak sağladığı görülmektedir (Demiryürek, 2018; Beyoğlu, 2011; Akcan, Kuncan ve Minaz, 2020). Bu programda, PV sistemlerinin çalışması, boyutlandırması, benzetim modelinin oluşturulması ve veri analizi için bir PC yazılım paketidir. $\mathrm{Bu}$ yazılım, şebekeye bağlı olan veya bağlı olmayan sistemler için, PV bileşenler altyapısıyla kullanabileceğimiz geniş bir meteorolojik veri tabanı sunmaktadır. $\mathrm{Bu}$ yazılım mimarlar, mühendisler ve araştırmacılara yönelik olarak hazırlanmış ve eğitim için yararlı olabilecek bir programdır.

Başlıca özellikler sıralanırsa:

- Şebekeden bağımsız PV sistemlerinin tam tasarımı

- Şebekeye bağlı PV sistemlerinin tam tasarımı

- PV paneller, invertörler ve meteorolojik verileriyle bütünleşik veri tabanı

- Faydalı 3D uygulaması ile yakın gölgelerin simüle edilmesi

- PVGIS NASA veri tabanlarından ışınlama verilerinin kullanılmasi

- Ekonomik değerlendirme ve geri ödeme hesaplarının yapılmas1 21].

CSV dosya formatında hesaplamaların aktarılmasıdır [19-

Sistemin PVSyst programı ile modellenmesinin adımları kısaca özetlenecek olursa; ilk olarak Şekil 7 ile gösterilen sayfa açılış penceresidir.

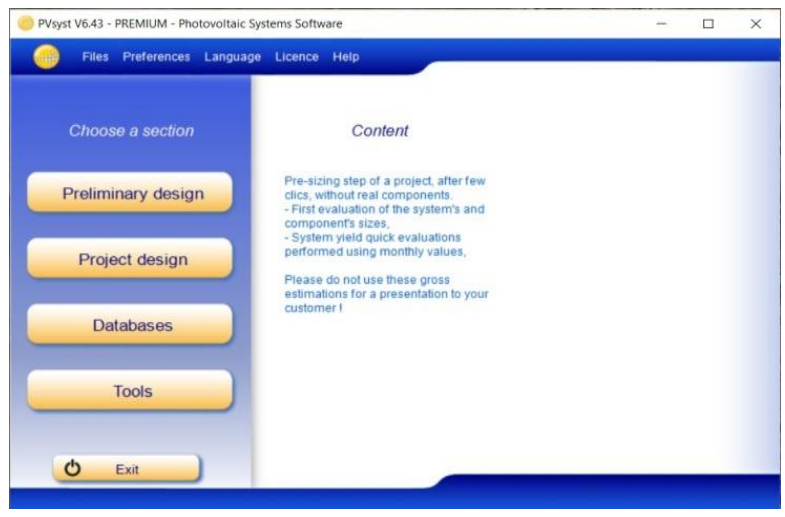

Şekil 7. PVSyst programı ana ekran görünümü
Açılış ekranından "Database" seçilerek Şekil 8 ile gösterilen ekrandan açılır. Bu sayfada "Geographical Sites" sekmesi seçilir. Bu seçim ile ekranda bir harita açılır. Açılan haritadan istenilen yer işaretlenir. $\mathrm{Bu}$ sayede program seçilen noktanın koordinat bilgilerini verir. $\mathrm{Bu}$ aşamada "Google earth'dan" işaretlenen noktanın rakım bilgisi programa kaydedilerek sisteme bu bilgi yüklenir. Sonrasında "Meteo Tables and Graphs" sekmesinden Meteonorm 7.1 (2003-2011) veri tabanından bölgenin meteoroloji verileri sentetik olarak üretilir. "Import Meteo Data" sekmesinden aldığımız meteoroloji verileri programa yüklenir.

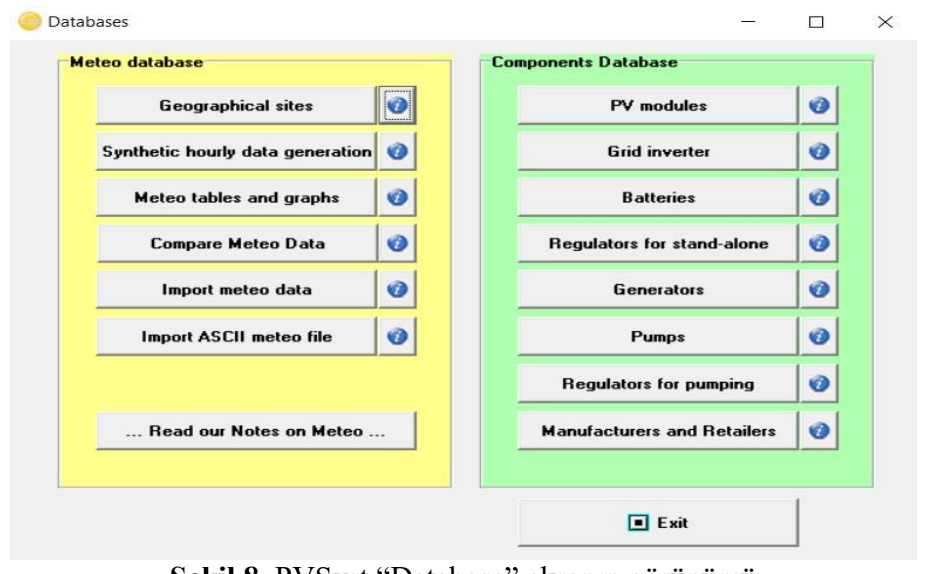

Şekil 8. PVSyst “Database” ekranın görünümü

Benzetim modellerini oluşturmak için öncelikle Şekil 9 ile gösterilen "System Variant" ekranında "Orientation" sekmesinde yer alan optimum açılar hesaplatılır.

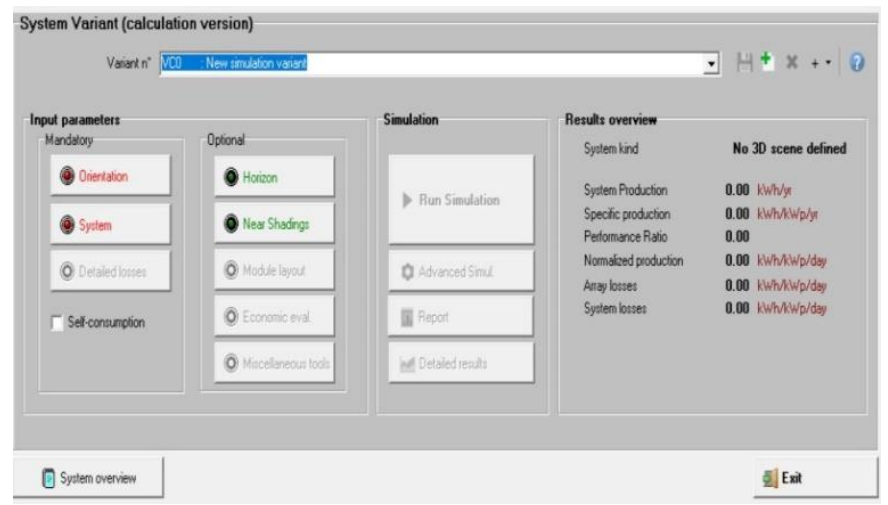

Şekil 9. PVSyst "System Variant” ekranın görünümü

Sabit sistem için hesaplanan açı ve çift eksen takip sistemi için hesaplanan açılar Şekil 10 ile gösterilmiştir.

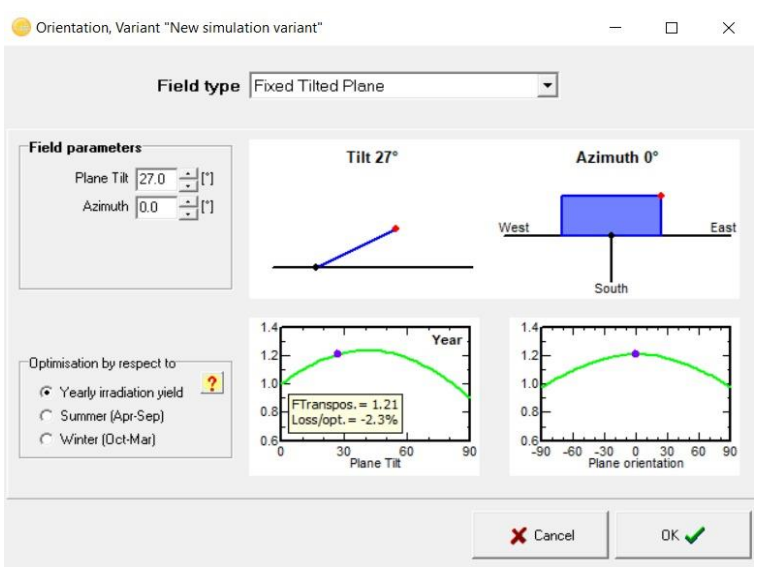

(a) 


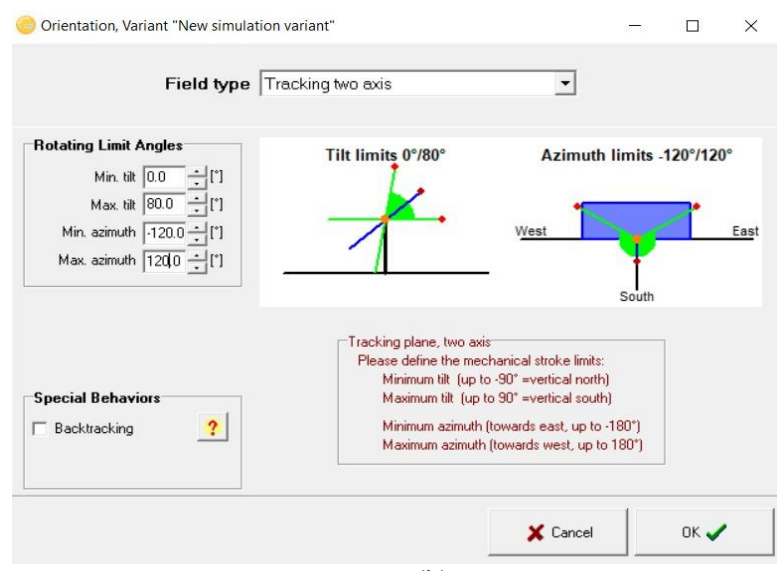

(b)

Şekil 10. (a) Sabit Eksenli, (b) Çift Eksenli sitemlerin açı hesaplarının yapıldığı ekran görünümü

Benzetim modeline ait çeşitli versiyonları oluşturmak için ikinci olarak "System" sekmesinden fotovoltaik sistem bileşenlerinin seçimi için "Component Database" kısmındaki ilgili sekmelere girilerek sistem verileri tamamlanır ve böylece benzetim modeli çalıştırılmış olur. Benzetim modelinin çalıştırılmasının ardından tüm sonuçlar bir rapor halinde elde edilir (Yadav, Kumar ve Chandel, 2015; Haydaroğlu ve Gümüş, 2016; Demiryürek, Arifoğlu ve Bolat, 2020).

\section{Araştırma Sonuçları ve Tartışma}

\subsection{PVSyst Benzetim Modeli Sonuçları}

\subsubsection{Sabit Eksenli Sistem Versiyonu}

Sabit eksenli güneş üretim santralinin araziye yerleştirilmiş görseli Şekil 11 ile verilmektedir. Yine aynı şekil içerisinde fotovoltaik sisteme ait panel, evirici, açı, AA güç ve DA güç bilgilerine yer verilmiştir. Üretim verileri ve performans oranları Şekil 12 (a) ile ve sabit eksenli sistem kullanılması durumdan PVSyst programı kullanılarak elde edilen benzetim sonuçlarına göre Konya iline ait yıllık olası üretim grafiği ise Şekil 12 (b) ile gösterilmektedir.

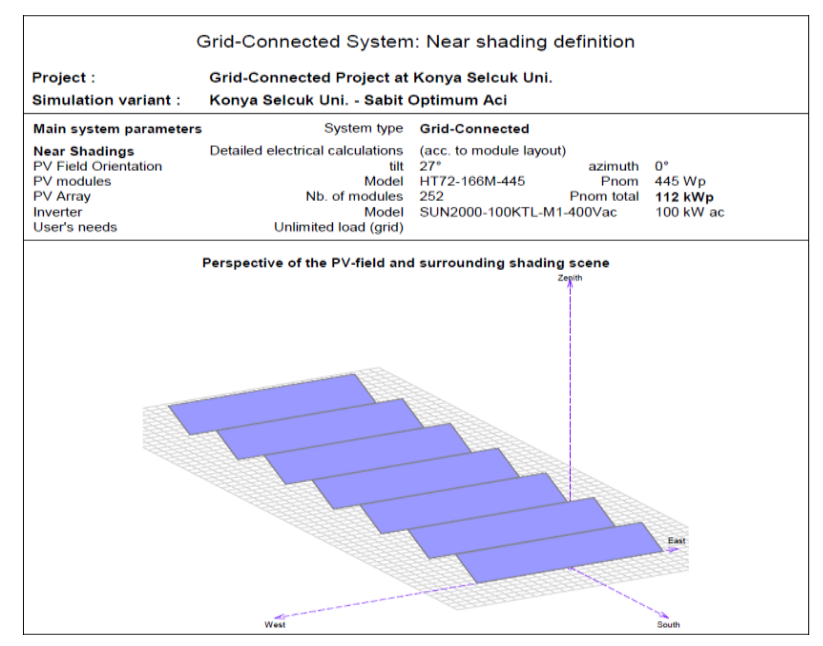

Şekil 11. Sabit eksenli güneş üretim santralinin arazi şartlarında yerleştirilmesi

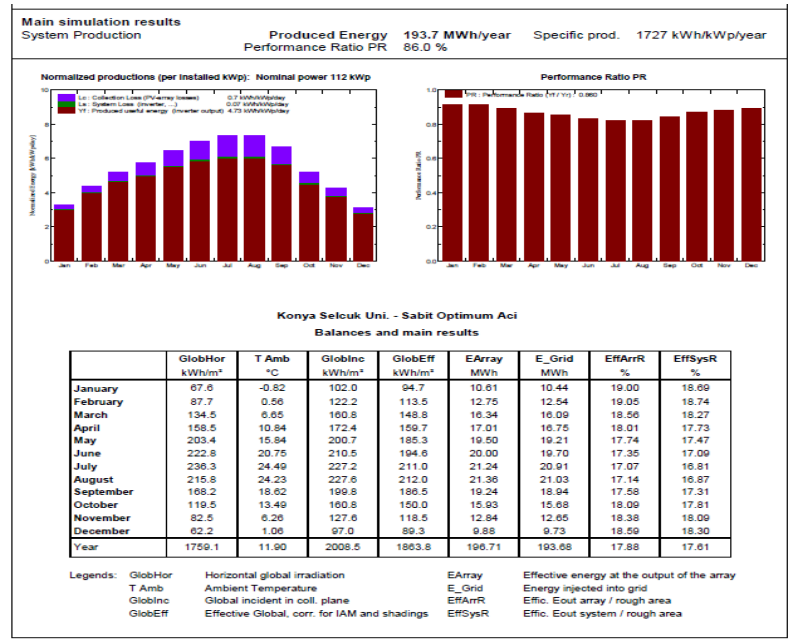

(a)

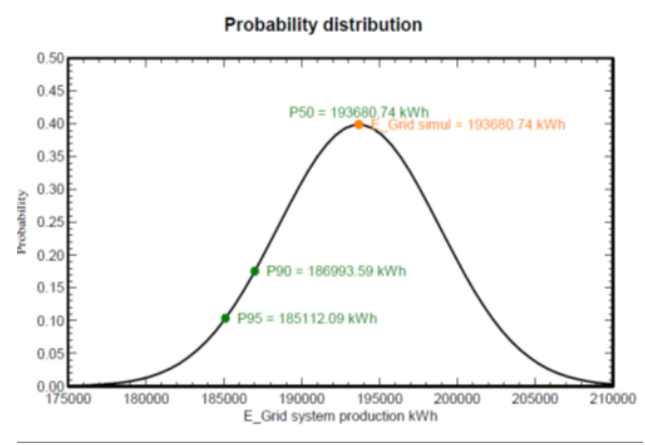

(b)

Şekil 12. (a) Sabit eksenli durumda Konya iline ait üretim ve performans verileri (b) Konya iline ait yıllık üretim grafiği

\subsection{2. Çift Eksenli Sistem Versiyonu}

Çift eksenli güneş üretim santralinin araziye yerleştirilmiş görseli ve fotovoltaik sistemde kullanılan panele, eviriciye, açıya, AA güç ve DA güç bilgilerine Şekil 13 ile verilmektedir. Çift eksen kullanılması durumunda üretim verileri ve performans oranları Şekil 14 (a) ile gösterilirken çift eksenli sistem kullanıldığında PVSyst programı kullanılarak elde edilen benzetim sonuçlarına göre Konya iline ait yıllık olası üretim grafiği Şekil 14 (b) ile gösterilmektedir.

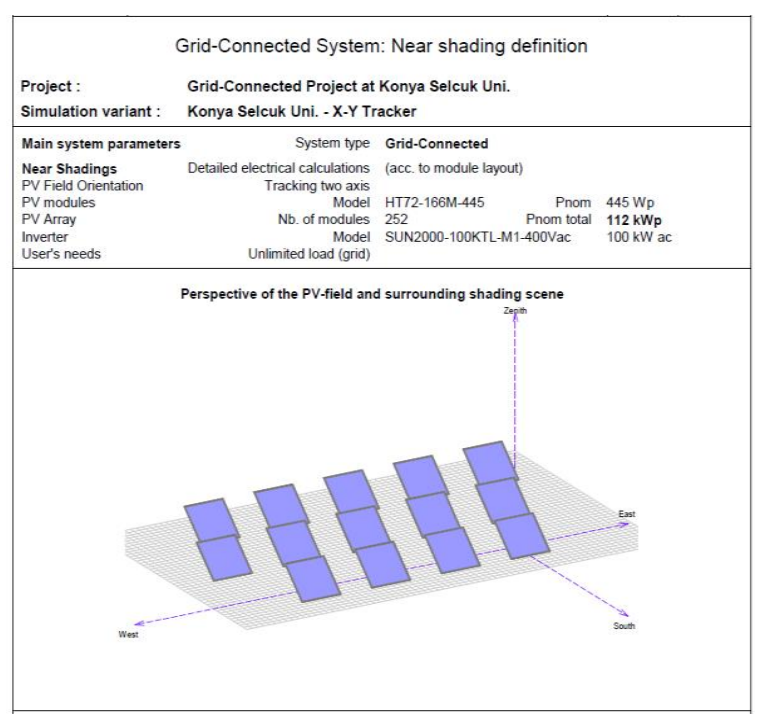

Şekil 13. Çift eksenli güneş üretim santralinin arazi şartlarında yerleştirilmesi 


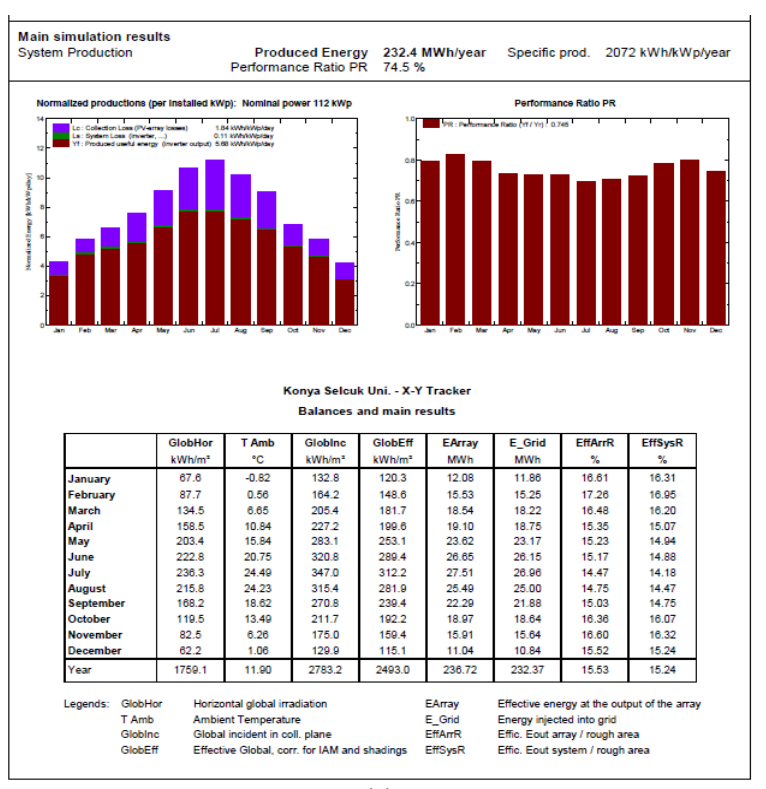

(a)

Probability distribution

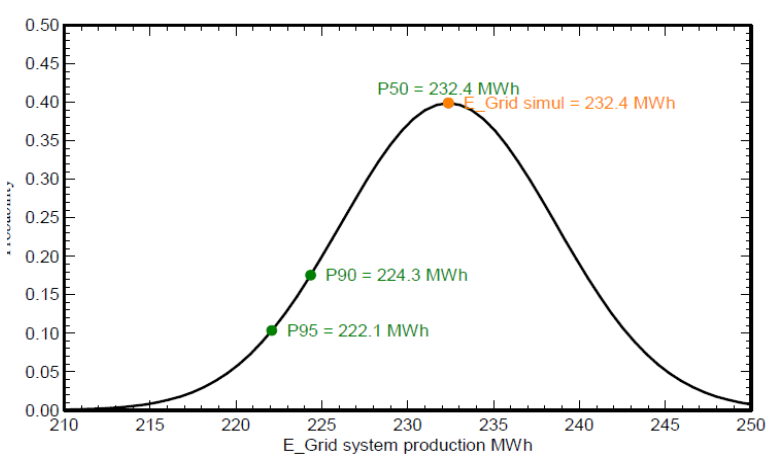

(b)

Şekil 14. (a) Çift eksenli durumda Konya iline ait üretim ve performans verileri, (b) Konya iline ait yıllık üretim grafiği

\section{Sonuç}

Bu çalışmada PVSyst yazılım programı kullanılarak; güneş enerji potansiyeli yüksek olan Konya ilinde güneşten enerji üretimi yapan iki farklı sistemin modellenmesi, sistemlerin üretim verilerini karşılaştırılması ve PV sistem tasarımının nasıl yapılacağını karşılaştırılmalı olarak sunulmuştur.

Araştırmada PVSyst programının 6.43 sayılı sürümü kullanılmıştır. Seçilen konumda iki farklı sistem verileri sisteme yüklenmiştir. Aynı panel ve evirici kullanılmış olup sistem kayıplarının da aynı olduğu kabul edilmiştir. Sabit eksenli sistemde optimum açı 270 -Azimut 00 iken hareketli sistemde açı dikeyde 00, 800 ve azimut açısı -1200, 1200 olarak tanımlanmıştır. Programda veriler bu şekilde yüklenerek benzetim modeli yapılarak sonuçlar raporlanmıştır. Raporda sabit eksenli güneş sisteminde yıllık üretim miktarı 193.7 $\mathrm{MWh} / \mathrm{y} 1 \mathrm{l}$, çift eksenli güneş takipli sistemde ise $232.4 \mathrm{MWh} / \mathrm{y} 1 \mathrm{l}$ olduğu görülmüştür. Çift eksenli sistemin \%16,7 olarak daha fazla enerji ürettiği sonucuna varılmıştır

\section{Kaynakça}

Adak, S., Cangi, H., \& Yılmaz, A.S.(2019). Fotovoltaik sistemin çıkış gücünün sıcaklık ve 1şımaya bağlı matematiksel modellemesi ve simülasyonu. Uluslararası Mühendislik Araştırma ve Geliştirme Dergisi,11(1), s. 316-327.

Akcan, E., Kuncan, M., \& Minaz, M.R.(2020). 2018 PVSyst yazılımı ile $30 \mathrm{kw}$ şebekeye bağlı pv sistemin modellenmesi ve simülasyonu. Avrupa Araştırma ve Bilim Dergisi, 18.

Akkaya, S. (2019). Samsun, Bayburt ve Mersin illerine kurulabilecek güneş enerjisi santrallerinin modellenmesi (Yüksek Lisans Tezi, Ordu Üniversitesi Fen Bilimleri Enstitüsü)

Aksangör, N.N.(2019). nkara şartlarında bir pv sistemin pvsyst programı yardımı ile performans analiz (Yüksek Lisans Tezi Gazi Üniversitesi. Fen Bilimleri Enstitüsü)

Beyoğlu, M.F.(2011). Balıkesir ilinde çift eksenli güneş takip sistemi ile sabit eksenli pv sistemin verimlerinin karşılaştırılması (Enstitüsü Yüksek Lisans Tezi, Balıkesir Üniversitesi, Fen Bilimleri)

Cuce, E, Cuce, P. M., Karakas, I. H., \& Bali T. (2017).An accurate model for photovoltaic (PV) modules to determine electrical characteristics and thermodynamicperformance parameters. Energy Convers. Manag. , 146, s. 205-216.

Demiryürek, H.K. 2018. 200kwp kurulu güçteki lebit enerji güneş santralinin pvsyst ile tasarımı ve üretim değerleri ile simulasyon değerlerinin karşılaştırılması (Yüksek Lisans Tezi, Sakarya Üniversitesi, Fen Bilimleri Enstitisü)

Demiryürek, H.K., Arifoğlu, U., Bolat, M.(2020). Lebit enerji güneş santralinin Pvsyst Programı ile analizi. BEÜ Fen Bilimleri Dergisi, 9(3), s.1351-1363.

Demirtaş, M.(2006). Bilgisayar kontrollü güneş takip sisteminin tasarımı ve uygulaması. Gazi Üniversitesi Teknik Eğitim Fakültesi, Elektrik Eğitimi Bölümü, Politeknik Dergisi, 9(4), s. 247-253,

Haydaroğlu, C., Gümüş, B.(2016). Dicle Üniversitesi güneş enerjisi santralinin PVsyst ile simülasyonu ve performans parametrelerinin değerlendirilmesi. Dicle Üniversitesi Mühendislik Fakültesi Mühendislik Dergisi, 7(3), s.491-500.

İșen, E., Koçhan Ö. (2020). Fotovoltaik panelin tek diyotlu modellenmesi. Müh. Bil ve Araş. Dergisi, 2(1).

Kırcıoğlu, O., Yıldız, A.B.(2015). Fotovoltaik panelin tek diyotlu eşdeğer devresine ait büyük sinyal analizi. TMMOB Elektrik Mühendisleri Odası Enerji Verimliliği ve Kalitesi Sempozyumu.

Kocalmis Bilhan, A., Caliskan, A., Unal, S.(2016). Simulation of a photovoltaic panels by using Matlab/Simulink", ECAI-2016, 8(2), s. 1-6.

MGM (2021, Mart). Radyasyon Verileri [Basın Bülteni]. Erişim adresi https://www.mgm.gov.tr/genel/meteorolojiyegir.aspx

Nunes, H G G., Silva, P N C., Pombo J A N., Mariano, S J P S.\& Calado, M R A.(2020). Multiswarm spiral leader particle swarm optimization algorithm for PV parameter identificatio. Energy Convers. 225:113388.

Oral, G., Uçan, O.N.(2012). Güneș takip sistemleri ve prototip gerçekleştirilmesi. İstanbul Aydın Üniversitesi Dergisi, 4(15), sayfa $1-14$.

Sarsıcı, N.(2020). Karabük ilinde güneş enerjisi santrali (ges) kurulabilecek alanların çok ölçütlü karar analizi ile tespiti (Yüksek Lisans Tezi, Karabük Üniversitesi, Coğrafya Anabilim Dali).

TEİAŞ (2021,Mart). Kurulu Güç Raporları [Basın Bülteni]. Erişim Adresi https://www.teias.gov.tr/tr-TR/kurulu-guc-raporlari

Uzunok, S. (2007) PV modüllerin elektrik enerjisi üretiminde güneş takip sisteminin etkisinin incelenmesi (Yüksek Lisans Tezi, Mustafa Kemal Üniversitesi Fen Bilimleri Enstitisü)

Yadav, P., Kumar, N.,\& Chandel, S.S.(2015). Simulation and performance analysis of a lkwp photovoltaic system using Pvsyst Computation of Power, Information And Communication Conf., 3(5), s. 358-363. 